\title{
Optimum parameters for treating coolant wastewater using PVDF-membrane
}

\author{
Erna Yuliwati, ${ }^{1, *}$, Ahmad Fauzi Ismail ${ }^{2}$, Amrifan Saladin Mohruni ${ }^{3}$ and Agung Mataram ${ }^{3}$ \\ ${ }^{1}$ Department of Chemical Engineering, Faculty of Engineering, Universitas Sriwijaya, Indralaya, Indonesia \\ ${ }^{2}$ Advanced Membrane Technology Research Center, Universiti Teknologi Malaysia, 81310 UTM, Skudai Johor, Malaysia. \\ ${ }^{3}$ Department of Mechanical Engineering, Faculty of Engineering, Universitas Sriwijaya, Indralaya, Indonesia
}

\begin{abstract}
Chemical oxygen demand (COD removal on ultrafiltration membrane were studied from treating of coolant wastewater. The membranes were fabricated via the dry-jet wet spinning method. The experiment was conducted using synthetic coolant wastewater as effluent, and an experimental set-up consist of membrane reservoir was used throughout the investigation. Deposition and accumulation of suspended solids on the membrane surface during filtration were prohibited with continuous aeration. Membrane performance was measured as well as flux and COD removal efficiency. The RSM was performed to investigate the optimised process conditions for treating coolant wastewater. Results using RSM-approximation have demonstrated the improvement in COD removal of $99.63 \%$. This improvement is achieved by optimised process conditions of mixed liquor suspended solids (MLSS) concentration, air bubble flow rate (ABFR), hydraulic retention time (HRT) and $\mathrm{pH}$ at $6.00 \mathrm{~g} / \mathrm{L}, 3.05 \mathrm{ml} / \mathrm{min}, 280.50 \mathrm{~min}$, and 6.50 respectively.
\end{abstract}

\section{Introduction}

Wastewater streams typically contain many regulated inorganic and organic contaminants that can restrict its use or disposal thereof. Standards promulgated by the state agency that regulates the maximum content of contaminants in wastewater streams disposed into publicly owned treatment works or discharged into waste injection wells have become increasingly more strict. For instance, in Indonesia, the effluent discharged from industrial sectors should comply with the national primary regulator of the discharged standard from Standard Environmental Regulation, 2015 [1]. For attaining of these limits, the palm oil wastewater treatment needs additional tanks and equipment, but in many cases, the refineries are located in populous areas with little space for expansion. Technologies, which can treat large quantities of wastewater with relatively small requirements are essential. The developed membrane technology can completely retain biomass and operate with high suspended solids concentration.

The removal of organic wastes from wastewater becomes essential increasingly, and submerged ultrafiltration finds its application in this area [2]. The membrane is promising to be used in water and wastewater treatment due to its high packing density and ease of module manufacture and operation. In this device, hollow fibre membranes are directly immersed in the feed reservoir with the withdrawal of permeate through the fibres by the application of vacuum on the outlet of the fibre lumen [3-5]. According to the reports, machining oil wastewater was characterised by the presence of several substances, namely, oil and grease, chemical oxygen demand (COD), total organic carbon (TOC), sulphide, and total suspended solids (TSS) [6]. The process efficiency in the membrane filtration is generally affected by many factors such as aeration flow rate; mixed liquor suspended solids (MLSS) concentration, $\mathrm{pH}$, and hydraulic retention time (HRT). As well, separation efficiency, flux, and COD are considered as results of this study.

Table 1. The composition of synthetic coolant wastewater with standard deviation (S.D) and standard for wastewater and water discharge [1].

\begin{tabular}{|c|c|c|}
\hline $\begin{array}{c}\text { Constituent, } \\
\text { unit }\end{array}$ & $\begin{array}{c}\text { Concentration } \\
\text { (S.D) }\end{array}$ & Standard \\
\hline $\mathrm{pH}$ & 6.7 & $5.5-9$ \\
\hline $\mathrm{COD}, \mathrm{mg} / \mathrm{L}$ & $555.0(0.25)$ & 200 \\
\hline $\mathrm{TOC}, \mathrm{mg} / \mathrm{L}$ & $29.1(1.02)$ & \\
\hline $\begin{array}{c}\text { Suspended } \\
\text { Solids, } \mathrm{mg} / \mathrm{L}\end{array}$ & 20 & 100 \\
\hline
\end{tabular}

\footnotetext{
* Corresponding author: erna.yuliwati@unsri.ac.id
} 


\section{Experimental}

The properties of PVDF membranes used in this work have been described in the previous study in detail [5]. As a semi-crystalline polymer, PVDF generally exhibits more complicated phase separation behaviour than amorphous polymer. The addition of $\mathrm{SiO}_{2}$ affected as a modifier for PVDF membranes since they are chemically and thermally stable with larger surface area, highly miscible, fine suspendability in aqueous solution and relatively environmentally inert. Researchers have been carried out on their addition to PVDF matrix have been found to a promising modifier to improve the permeability and selectivity of PVDF membrane [7-9]. Synthetic coolant wastewater was prepared to be used as feed solution in ultrafiltration experiments as shown in Fig 1.

\subsection{Experimental setup and procedure}

The lab-scale experimental set-up shown in Figure 1 was used in this work. The submerged membrane separation system consisted of a feed reservoir of the $14 \mathrm{~L}$ volume, hollow fibre bundles, a peristaltic pump, a permeate flow meter, and a permeate collector.

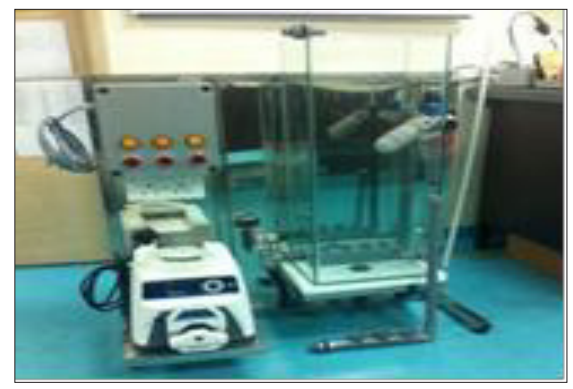

Fig. 1. Ultrafiltration membrane unit

The filtration experiments were conducted at room temperature and under vacuum on the permeate side $(0.5$ bar abs). The membrane was created using a peristaltic pump (Master flex model 7553-79, Cole Palmer) with the permeate being withdrawn from the open end of fibres and a constant transmembrane pressure (TMP) of 0.5 bar was maintained to let water permeate from outside to the inside of the hollow fibre. The continuous aeration produced a turbulent flow, which could decrease the cake layer thickness and the average particle size [7].

\subsection{Analytical methods}

Membrane performance of Flux was tested by membrane bundle that having $10.48 \mathrm{dm}^{2}$ of membrane surface area. The pure water flux was measured at $100 \mathrm{kPa}$ after the flux was steady, then calculated as

$$
F=V / A t
$$

where $\mathrm{F}$ is the pure water flux $\left(\mathrm{L} / \mathrm{m}^{2} \mathrm{~h}\right), \mathrm{V}$ the permeate volume (1), A the membrane surface area $\left(\mathrm{cm}^{2}\right)$ and $\mathrm{t}$ is the time (h).
Average pore size, $r_{m}$ was determined by the filtration velocity method, in which pure water flux of the wet membrane was measured by applying pressure ( $0.1 \mathrm{MP})$ for a limited period $(20 \mathrm{~h})$. It represents the average pore size along the membrane thickness $(\ell)$ that was the difference between the external radius and an internal radius of the hollow fibre membrane. According to Guerout-Elford-Ferry equation, rm could be calculated by Yu et al., 2006 [8].

$r_{m}=\sqrt{\frac{(2.9-1.75 \varepsilon) \times 8 \eta \ell Q}{\varepsilon \times A \times \Delta P}}$

where $\eta$ is water viscosity $\left(8.9 \times 10^{-4} \mathrm{~Pa}\right), \ell_{\text {is }}$ the membrane thickness $(\mathrm{m}), \Delta P$ is the operating pressure $(0.1 \mathrm{MPa}), \varepsilon$ is the porosity of the membrane $(\%), Q$ is the volume of permeate water per unit time $\left(\mathrm{m}^{3} \mathrm{~s}^{-1}\right), A$ is the effective area of membrane $\left(\mathrm{m}^{2}\right)$.

COD concentrations were measured using a spectrophotometer (DR 5000, HACH) in accordance with the standard procedures of method 8006 (Photometric method) and method HR TNT 10031 (Salicylate method), respectively. During the operation with high organic loading rates, the concentrations were evaluated daily, and sampling was carried out three times a week again. The COD removal efficiencies were calculated by Eqs. (1)

$$
\text { COD removal }(\%)=\frac{C O D_{0}-C O D}{C O D_{0}} \times 100
$$

where $C O D_{o}$ and $C O D$ are the initial COD concentration of the feed synthetic palm oil wastewater and the COD concentration of permeate produced.

A field emission scanning electronic microscope (FESEM, Hitachi Model S-520 Japan) was employed to observe a cross-section of the prepared PVDF membranes [9]. Prior to analysis, the membranes were cryogenically fractured in liquid nitrogen and then spattered with platinum. The FESEM micrographs were taken at certain magnifications.

\subsection{Response surface methodology (RSM)}

Response surface methodology (RSM) is a collection of mathematical and statistical techniques, commonly used for improving and optimising processes. It can be used to evaluate the relative significance of several affecting factors in the presence of complex interactions. When a combination of several independent variables and their interactions affects desired responses, RSM is an effective tool for optimising the process [10]. RSM uses an experimental design such as the central composite design (CCD) to fit a model by least squares technique. This methodology optimises COD removal in submerged hollow fibre membrane process. The Design Expert software is used for the statistical design of experiments and data analysis and performed in duplicate [11]. The four most important operating variables (factors), air bubble flow rate $\left(\mathrm{x}_{1}\right)$, hydraulic retention time $\left(\mathrm{x}_{2}\right)$, mixed liquor suspended solids concentration $\left(\mathrm{x}_{3}\right)$, and $\mathrm{pH}\left(\mathrm{x}_{4}\right)$, 
are optimised. The study ranges (levels) are chosen as coded values for $\mathrm{x}_{1}, \mathrm{x}_{2}, \mathrm{x}_{3}, \mathrm{x}_{4}$ are set at 5 levels $-2,-1$ (minimum), 0 (central), +1 (maximum), and +2 . Four dependent parameters are analysed as responses. Namely, COD removals, where achieved permeate flux was 145.7 $\mathrm{L} / \mathrm{m}^{2} \mathrm{~h}$, in order to obtain optimum process condition.

In RSM, a model with the form of Eq. (3) is fitted to experimental data and, by optimisation, the coefficients in the model are calculated. To identify the right model that can fit the data, it can be started with the simplest model forms like first- and second-degree Scheffe's polynomial [12]. After testing these models for adequacy of fit, they were augmented to simplex centroid and special quartic models by adding the appropriate terms. In this study, the quartic model used for predicting the optimal point is as follows

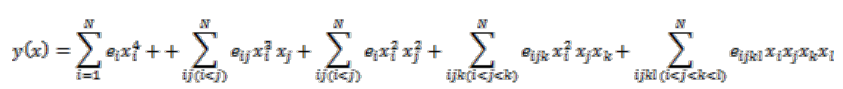

where $y$ is the response variable, $e_{i}, e_{i j}, e_{i j k}$, and $e_{i j k l}$ are the polynomial coefficients of the model, $\mathrm{x}_{\mathrm{i}}, \mathrm{x}_{\mathrm{j}}, \mathrm{x}_{\mathrm{k}}$ and $\mathrm{x}_{\mathrm{l}}$ are the coded levels of the independent variables [10]. All these coefficients variables are analysed by multiple regression analysis, and the response contour plot is generated using the software Design-Expert. The validity of the selected model used for optimising the process parameters has to be tested using analysis of variance (ANOVA) that is determined by performing the Fisher's statistical test.

\section{Results and discussion}

\subsection{Membrane structure and morphology}

Properties of the membrane can be shown in Table 2. Based on analysis of structural and characterisation of PVDF membrane.

Table 2. Membrane properties

\begin{tabular}{|c|c|}
\hline Parameter & Membrane \\
\hline Membrane configuration & Hollow fibre \\
\hline Membrane material & PVDF/SiO 2 \\
\hline Outer diameter $(\mathrm{mm})$ & 1.2 \\
\hline Inner diameter $(\mathrm{mm})$ & 0.6 \\
\hline Pore size $(\mathrm{nm})$ & 35.2 \\
\hline Membrane area $\left(\mathrm{dm}^{2}\right)$ & 10.48 \\
\hline
\end{tabular}

The membranes were obtained based on the size of outer and inner diameter, average pore size and membrane surface area. It showed that $\mathrm{SiO}_{2}$ had modified the nanoporous membrane pore size. Improvement of membrane morphology is observed by adding of $\mathrm{SiO}_{2}$. The result shows that the permeate flux of the membrane was better (flux value of 92.4\%) as compared to the neat PVDF membrane (flux value of $84.3 \%$ ). This improvement was caused by the change of membrane morphology of PVDF membrane. It is observed for adding $\mathrm{SiO}_{2}$ particles, may affect the interaction between $\mathrm{SiO}_{2}$ particles and PVDF chains. Generally, the addition of nanofillers into PVDF matrix is due to the agglomeration phenomena. This phenomenon is owing to the natural characteristic of the nanofillers (such as small size and high surface energy) and the poor compatibility with hydrophobic OVDF bulk. At present, the dispersion of nanofillers for the preparation of PVDF-inorganic composite membrane, usually achieved by strong mechanical stirring. They have a unique ability to bond polymers with dissimilar materials such as silica. The bond thus formed has good initial strength as demonstrated by the failure of the composite by polymer rupture and the bond exhibits excellent retention of strength even after severe environmental ageing.

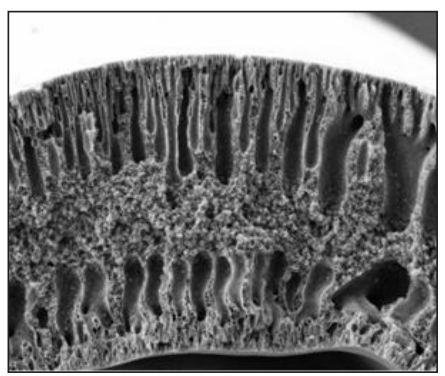

Fig. 2. FESEM images of the cross-section (mag 500x) of $\mathrm{PVDF} / \mathrm{SiO}_{2}$ membrane

Fig.2 illustrated that $\mathrm{SiO}_{2}$ affects the mass transfer during the phase inversion process. The cross-sectional images of hollow fibres consist of finger-like macrovoids extending from both inner and outer walls of the hollow fibre, and an intermediate sponge-like layer. This phenomenon can be explained by the kinetic effect on the rate of solvent-nonsolvent exchange in the phase inversion process. At lower $\mathrm{SiO} 2$ concentration (1\%), an increase in the amount of $\mathrm{SiO}_{2}$ tends to draw more water into the polymer dope, resulting in an increase in the length of finger-like macrovoids and decrease in the thickness of the intermediate sponge-like layer.

\subsection{Statistical analysis}

The Design Expert software was used to design the experiments and together with their experimental and predicted values of COD removal. The second-order polynomial regression model containing 4 linear, 4 quadratic, and 6 interaction terms plus 1 block term was employed by using RSM. This model was found to be significant with $\mathrm{R}^{2}=0.99$. Joglekar and May [10] also suggested that for a good fit of a model, $\mathrm{R}^{2}$ should be at least 0.80 . The $\mathrm{R}^{2}$ for these response variables were higher than 0.80 , indicating that the regression models explained the reaction well. However, its lack of fit was significant $(\mathrm{P}=0.0229)$, suggesting that this model not accurately represent the data in the experimental region. Therefore, 
each factor had five levels, up to quartic terms could be included in the model [11]. An empirical relationship between the response and the variables expressed by the following fitting the fourth equation degree. The experimental results were evaluated and approximating function of flux and COD removal was obtained in the final equation in terms of a coded factor are:

$\mathrm{Y}_{2}=-208.48050+0.46 \mathrm{X}_{1}+0.79 \mathrm{X}_{2}+8.51 \mathrm{X}_{3}+0.28 \mathrm{X}_{4}+0.034$ $\mathrm{X}_{1} \mathrm{X}_{2}-0.095 \mathrm{X}_{1} \mathrm{X}_{3}-0.19 \mathrm{X}_{1} \mathrm{X}_{4}-0.77 \mathrm{X}_{2} \mathrm{X}_{3}-0.56 \mathrm{X}_{2} \mathrm{X}_{4}-$ $0.57 \mathrm{X}_{3} \mathrm{X}_{4}+0.067 \mathrm{X}_{1}^{2}-0.46 \mathrm{X}_{2}^{2}-3.40 \mathrm{X}_{3}^{2}-2.96 \mathrm{X}_{4}^{2}+0.11$ $\mathrm{X}_{1} \mathrm{X}_{2} \mathrm{X}_{3} 0.15 \mathrm{X}_{1} \mathrm{X}_{2} \mathrm{X}_{4}+0.11 \mathrm{X}_{1} \mathrm{X}_{3} \mathrm{X}_{4}-0.18 \mathrm{X}_{2} \mathrm{X}_{3} \mathrm{X}_{4}-0.074$ $\mathrm{X}_{1}^{2} \mathrm{X}_{2}+3.82 \mathrm{X}_{1}^{2} \mathrm{X}_{4}-0.29 \mathrm{X}_{1} \mathrm{X}_{2} \mathrm{X}_{3} \mathrm{X}_{4}-5.81 \mathrm{X}_{1}^{2} \mathrm{X}_{2}^{2}$

Empirical model equations are mathematical correlation models that can be employed to predict and optimise the COD removal within the range of variable factors of this experiment.

\subsection{Effect of pH-MLSS on COD}

Figure 3 shows that the $\mathrm{pH}$ exerts a remarkable influence on the biological removal of COD. The increase of $\mathrm{pH}$ values with increasing MLSS value resulted in the COD removal in the range $88-91 \%$. The average COD removal efficiencies had slightly different under $\mathrm{pH}$ conditions. $\mathrm{pH}$ had slightly affected the fatty acid composition in coolant wastewater. It does not lead to a sufficient supply of dissolved oxygen in acid or base conditions [12-13]. The oxygen is needed by aerobic microorganisms as electron acceptor.

COD removal increased slightly with increasing MLSS concentration. It was indicated that the lower MLSS concentration $(3.00 \mathrm{~g} / \mathrm{L})$ the microbial metabolism and COD removal were quite low. Addition to MLSS concentration to $8 \mathrm{~g} / \mathrm{L}$, the sludge increased and COD removal also increased caused by proper organic matter removal was achieved in the process regarding the characteristic of wastewater.
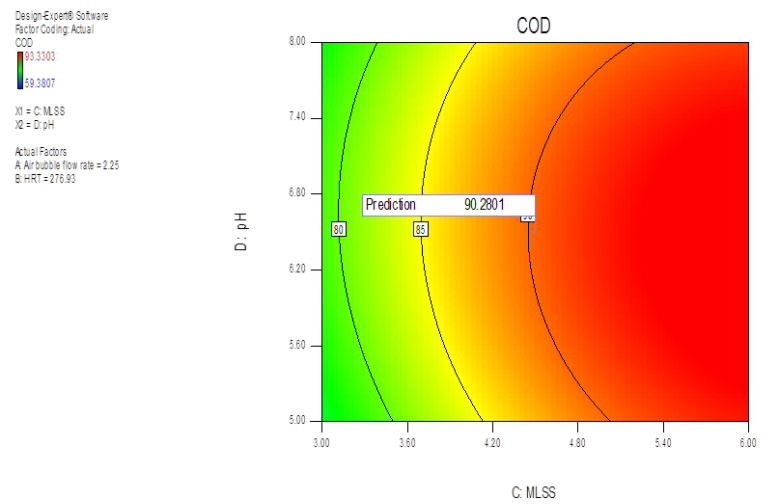

Fig. 4. Contour graph of COD from equation of effect the $\mathrm{pH}-$ MLSS

Place the figure as close as possible to the point where it is first referenced in the text. If there is a large number of figures and tables, it might be necessary to place some before their text citation. If a figure or table is too large to fit into one column, it can be centred across both columns at the top or the bottom of the page.

\section{Conclusions}

Full factorial design and central composite design of response surface methodology can be used to determine the significant variables and optimum condition for submerged ultrafiltration of coolant wastewater concerning the COD removal. Experimental results showed that a submerged ultrafiltration process using modified PVDF membranes has an excellent potential for refinery produced wastewater treatment. The quartic equation developed in this study shows the presence of a high correlation between observed and predicted values. Interestingly, 3-dimension response surface plots can be an excellent driven approach for visualising the parameter interaction. The optimum factor conditions were satisfied at ABFR of $2.25 \mathrm{ml} / \mathrm{min}$, HRT of $276.93 \mathrm{~min}$, the MLSS concentration of $4.50 \mathrm{~g} / \mathrm{L}$, and $\mathrm{pH}$ of 6.50 to resulted in COD removal of $90.28 \%$.

The approach of the statistical method has been testified to be a powerful tool for studying membrane ultrafiltration process. Further pilot-scale studies are required, and detailed study is needed to explore the remediation of coolant wastewater filtration.

This work was financially supported by the Ministry of research and technology and higher education of Republic Indonesia.

\section{References}

1. A.W. Zularisam, A.F. Ismail, R. Salim, M. Sakinah, T. Matsuura, Desalination 212, 1-3 (2007).

2. A. Mansourizadeh, A.F. Ismail, Chem. Eng. J. 165, 3 (2010).

3. A. Bottino, G. Capannelli, A. Comite, R. Mangano, Desalination 245 1-3 (2009).

4. M.L. Hami, M.A. Al-Hasyimi, M.M. Al-Doori, Desalination 216, 1-3 (2007).

5. M. Kobya, E. Demirbas, M. Bayramoglu, M. Sensoy, Water Air Soil Pollut, 215, 1-4 (2011).

6. I. Khouni, B. Marrot, R.B. Amar, Chem. Eng. J. 156, $1(2010)$.

7. K.J. Howe, M.M. Clark, Environ. Sci. Technol. 36, $16(2012)$.

8. E. Yuliwati, A.F. Ismail, T. Matsuura, M.A. Kassim, M.S. Abdullah, 283, Special Issue (2011).

9. D.M. Wardrop, R.H. Meyers, J. Statist. Plann. Inference 25, 1 (1990).

10. Design-Expert ${ }^{\circledR}$ Software Version 6 User's Guide, 2001.

11. Design-Expert ${ }^{\circledR}$ Software Version 8.0.5.2, 2011.

12. W.J. Lau, A.F. Ismail, Membr. Water. Treat. 1, 1 (2010).

13. E. Yuliwati, A.F. Ismail, T. Matsuura, M.A. Kassim, Desalination, 283, Dec. (2011). 